\title{
Reviewing the Research on Marginalization in Mathematics Education
}

Grace A. Chen and Ilana S. Horn

Vanderbilt University

\begin{abstract}
Author Note
This manuscript is based upon work supported by the Mindset Scholars Network's Inclusive Mathematics Environments Early Career Fellowship, with funding provided by a grant from the Bill \& Melinda Gates Foundation. The content is solely the responsibility of the authors and does not necessarily represent the views of the Mindset Scholars Network or the Bill \& Melinda Gates Foundation.
\end{abstract}




\begin{abstract}
In light of decades of research seeking to document and transform extensive injustices in mathematics education in the United States, we examine how different conceptualizations of which students are marginalized and by what processes they are marginalized in order to contribute to a more thorough, nuanced understanding of marginalization in mathematics education. To do so, we review literature theorizing marginalization across social identity categories and synthesize the disciplinary traditions they draw on and the mechanisms of marginalization they articulate. Findings from this review highlight the normality of marginalization in mathematics education, the material and ideological means of marginalization, and the interlacing of individual and structural sources of marginalization. As a result, we argue for critical bifocality in attending simultaneously to the processes of marginalization that occur in individual mathematics classrooms alongside the systemic structures that organize marginalization in society more broadly.
\end{abstract}

Keywords: mathematics education, inequity, marginalization, racism, sexism, classism 


\section{Reviewing the Research on Marginalization in Mathematics Education}

Mathematics education in the U.S. is rife with injustice: students' access to mathematical learning opportunities and student achievement are highly stratified; students' classroom experiences are frequently discouraging and dehumanizing; and students' mathematical knowledges and practices are widely ignored when they do not align with dominant ways of learning and doing. Despite decades of calls for increasing attention to these injustices and decades of work towards fairer and more just forms of mathematics education, some students remain far more likely to experience these injustices than others. Mathematics education researchers commonly refer to such students as being marginalized or as being from marginalized backgrounds, but marginalization is often used as a shorthand for particular social markers - such as racial or gender identities-and is rarely accompanied by explicit theories of why and how some students and not others come to be marginalized (or identified as marginalized). In this paper, we synthesize literature on marginalization in mathematics education seeking insights about what we, as a field, have learned from decades of research. By doing so, we hope to offer our fellow scholars a clearer conceptual basis for future research.

To this end, we review how mathematics education researchers have theorized marginalization. We focus on papers using the keyword "marginalization," because this term acknowledges that power is at play in centering some people and relegating others to the margins and yet is agnostic on how relations of power get enacted. By contrast, a broader keyword like "inequity" is often used to merely describe the existence of disparate outcomes or different positionings. Alternately, more specific keywords like "oppression" already take a stance on the causes of injustice (the existence of an oppressor), and would thus be less generative in identifying diverse theoretical perspectives on why and how injustice in mathematics education is perpetuated. Reading across heterogenous perspectives can inform a more detailed and nuanced understanding of how marginalization is produced and/or 
perpetuated in $\mathrm{K}-12$ mathematics classrooms and consequently, implications for how to work towards justice in mathematics education. Specifically, we aim to answer the following research questions:

1. Why and how are students marginalized in K-20 mathematics classrooms? That some students experience marginalization in mathematics classrooms has been welldocumented, through studies using everything from large-scale quantitative studies to qualitative narratives. But what causes this marginalization? How does this marginalization happen? Answering these questions - or at least, identifying theories for how these questions could be answered-creates opportunities for circumventing, interrupting, or reversing the processes by which students are marginalized.

2. When researchers say marginalized students, who exactly are they talking about? Whose marginalization in K-20 mathematics classrooms has been documented and/or theorized? Do theories of marginalization vary based on whose marginalization is being theorized?

We address these questions by describing how different disciplinary traditions in mathematics education account for marginalization at different grain-sizes (micro-, meso-, macro-) of social interaction. We also consider whether these multi-level marginalization processes operate differently for learners given their different social locations and the intersection of their historically marginalized identity markers (e.g., race, gender, class). Our review suggests that: 1) marginalization is neither new nor abnormal; 2) the means of marginalization are both material and ideological; and 3) there are both individual and structural contributors to marginalization. From these claims, we argue that mathematics education researchers need to take up epistemologies, designs, and research methods that support critical bifocality (Weis \& Fine, 2012), views that attend to social processes of different grain sizes simultaneously to understand how they work together to contribute to marginalization. To do so, researchers should seek to identify the circuits through which broader social inequities are woven into 
communities, schools, classrooms, and interactions, ultimately shaping individuals' mathematical identities that are at the nexus of multilevel marginalization processes. As Weis and Fine implore us, social phenomena cannot be isolated from their micro-, meso- and macro-environmental fields, and rigorous social science research must attend to the simultaneity and mutual reinforcement of processes operating at different scales in order to more effectively counter them.

\section{Methods}

To explore our research question, the first author conducted a review of relevant literature in mathematics education. Aligned with our theoretical goals, she followed Kennedy's (2007) definition of a conceptual review as one that aims to "gain new insights into an issue" (p. 139), in contrast to a systematic review that aims to be an exhaustive search for the answer to a specific empirical question. Thus, she surveyed the literature with the goal of identifying and synthesizing a range of different ways that researchers in mathematics education conceptualize marginalization, rather than seeking to read every single published paper about marginalization in mathematics education. For example, scholars will undoubtedly note that there are far more articles about race and racism in mathematics education than were identified through the search logic described below, which is a limitation of the keywords used; because we foregrounded marginalization as a construct and searched for marginalization, many articles that used race or racism as keywords without using marginalization as a keyword were excluded. Because the intent of this paper is not to provide a comprehensive review of the research on race as a reason for marginalization in mathematics education, but instead to locate common theorizations of marginalization including those used by experts on race in mathematics education, we did not explore these excluded articles in depth. In this section, we describe the search logic used to identify focal articles for this conceptual review.

To begin, the first author selected ProQuest for its inclusion of multiple education databases, including ERIC, as well as other social science databases in which articles related to mathematics 
education might be archived. Searching ProQuest for peer-reviewed articles that included "mathematics education" or "mathematics classroom" and the term "marginalized" (including other forms such as "marginalization") in their title, abstract, and/or keywords yielded 87 articles, several of which were duplicates. She also eliminated articles that did not focus on students in K-20 mathematics classrooms, such as those studying "marginalized teachers" or the "marginalized history" of a particular mathematical idea. Next, she asked whether the articles took a stance on why or how students become marginalized, or whether they simply stated that some students are marginalized. For example, work on linguistically responsive education (e.g., Lucas et al., 2008) that takes marginalization as a given and concentrates on mitigating rather than theorizing it would have been excluded had it appeared in the search results. To be included, articles did not need to propose original theorizations; they could (and often did) cite other literature to explain, for example, how racism marginalizes students.

After applying these criteria, 29 articles remained in what we will refer to as the primary corpus for the review. Most of these articles alluded to existing theories of marginalization in their introduction and/or theoretical framework and then proceeded to report an empirical case study of some sort of intervention, such as a classroom pedagogical practice (e.g., creating concept raps in Young et al., 2018) or professional development for teachers (e.g., a graduate course on culture in Parker et al., 2017). For the most part, they did not develop theory themselves about why some students are marginalized in mathematics classrooms (exceptions: Battey \& Leyva, 2016; Bullock, 2018; de Araujo et al., 2018; Leyva, 2016) or the processes by which this marginalization happens (exceptions: Kotsopoulos, 2016; LangerOsuna, 2015).

To articulate how researchers in mathematics education understand marginalization, then, the first author searched for additional articles that focused specifically on theorizing the why and how of marginalization. To do so, she consulted the reference sections of these 29 articles, her personal library, and recommendations from the second author and other mentors, seeking foundational work such as 
highly cited conceptual papers, reviews, and meta-analyses aimed at generating theory. In alignment with our research questions, she looked primarily for references specific to mathematics. Therefore, she excluded work about, for example, general theories of anti-Blackness in schools, but she did use the Web of Science database to find articles specific to mathematics education that cited these more general papers. Often, key scholars emerged in particular fields (e.g., Mendick's work on gender; Nasir's work on culture), and she chose 1-2 of their most highly cited articles, because their arguments about the root causes and processes of marginalization typically did not change from article to article. A notable exception is Martin's work on race in mathematics education; he highlights different theories of marginalization in different articles, including the reflection of institutional racism in how students negotiate their mathematical identities (2009), mathematics as a racial project (2013), and equity as a delusion "rooted in the fictions of white imaginaries" (2019, p. 460). We will refer to this additional set of papers as the supplemental corpus for the review. The final dataset included 29 articles in the primary corpus and 23 in the supplemental corpus (see Table 1). In the next section, we describe the theories of marginalization named or implied in the 52 reviewed articles, followed by an analysis of what researchers and practitioners can learn about marginalization in mathematics education by reading across all the included articles.

[Insert Table 1 about here]

\section{Review of Literature}

Few of the reviewed articles explicitly articulated the theories they drew on in understanding and suggesting responses to marginalization. However, we inferred their theories of marginalization by tracing the other literature they cited and studying the interventions they recommended. The reviewed articles varied widely in how they conceptualized why and how students are marginalized within K-20 mathematics classrooms, and also in the "isms" - social structures, identity markers, and histories-that they centered when identifying particular groups of students as marginalized. In this section, we first 
briefly summarize the theoretical traditions that appeared in the analysis as underlying research on marginalization in mathematics education, and then describe how these traditions intersected with the social categories that researchers foregrounded. In doing so, we aim to illustrate the variety of perspectives currently present in mathematics education research, indicating the complexity of marginalization as a phenomenon and therefore both the challenge of understanding it and the opportunity to consider it from multiple angles. Then, we offer some claims about theorizing marginalization based on looking across these varied approaches and make an argument for increased attention to critical bifocality in mathematics education research.

\section{Why and How Does Marginalization Happen? Discipline-based Explanations of Marginalization}

To conceptualize marginalization, researchers draw on theoretical traditions from different academic disciplines. Rather than attempting to elaborate each of these traditions in depth, we outline the distinguishing features of three primary perspectives-psychological, cultural, and political-as they are used in the reviewed research to provide context for the remainder of this section. The emergence of these three perspectives on marginalization in mathematics education is unsurprising given broader trends in mathematics education research. Psychological perspectives on teaching and learning mathematics, especially constructivist theories of learning, once prevailed (Silver \& Herbst, 2007), but the past few decades have seen a social turn in which researchers have attended more closely to "the cultural, historical, and social origins" of learning (Lerman, 2000, p. 31). A recent analysis of five decades of mathematics education research identifies a gradual decrease in psychology-based work on constructivism and particularly experimental psychology, along with a corresponding increase in work drawing on sociocultural theories and greater theoretical diversity overall (Inglis \& Foster, 2018). For example, scholars have called for-and some have taken-a further turn by theorizing the role of society in mathematics education, the sociopolitical, and the political (see Chazan et al., 2016; R. Gutiérrez, 2010/2013; and Pais \& Valero, 2012, respectively). 
In line with this theoretical diversity, the psychological, cultural, and political perspectives posit different sources of marginalization and therefore different ways marginalization is (re)produced in mathematics classrooms, which then have different implications for where and how to address marginalization. Table 2 identifies the most prominent disciplinary perspectives featured in each of the 29 articles in the primary corpus; note that studies of marginalization tend to use cultural and political theories more often than psychological ones. That said, these perspectives are not mutually exclusive; researchers can and do draw on multiple perspectives within the same article to direct their attention to multiple ways that students are marginalized in mathematics classrooms, thereby affirming the complexity of marginalization.

[Insert Table 2 about here]

Psychological Perspective. The psychological perspective was the least frequently used. It focused first and foremost on individuals as both the source of marginalization and as the solution to marginalization. This perspective did not (usually) deny the existence of structural oppression, but opted to focus on how individuals enact or react to it. For example, although individuals may be influenced by broader forces such as the prevalence of stereotypes in the media, those forces reflect individual biases held by those producing the media and are then acted upon by individuals. Researchers who drew on psychological theories often study constructs such as mindsets, attitudes, beliefs, expectations, biases, motivation, engagement, skills, and feelings of belonging or exclusion, as they appear in teachers and/or students. Typically, they hypothesized that marginalization in mathematics classrooms is (re)produced through the interplay of teachers' and students' individual psychologies. For example, a teacher may enact biases against certain students, such as by having low expectations for certain students due to beliefs about their mathematics ability, and individual students may respond by demonstrating resilience or vulnerability (Ireland et al., 2018), by not seeing themselves as math people (Oslund \& Barton, 2007), or by developing low self-esteem (Frost \& Wiest, 2007). From this perspective, then, 
marginalization is best addressed through individual-level interventions, such as shifting teachers' attitudes towards students or coaching students to feel a greater sense of belonging in mathematics spaces.

Cultural Perspectives. Researchers who took a cultural approach to theorizing marginalization in mathematics classrooms focused on what happens when individuals organize in groups. These researchers both defined culture differently and assumed different mechanisms by which culture contributes to marginalization. First, researchers operationalized culture three main ways: as stable qualities of social groups, as a set of identifiable practices, and as interactively (re)produced practices. In the stable view, culture is defined by relatively static features over time that particular groups of people share due to shared histories and shared cultural references (Francois \& Stathopoulou, 2012); for example, some researchers discussed the applicability of hip-hop pedagogies for Black youth, even as they are careful not to essentialize and assume that just because a student is Black, they will like hip-hop (Young et al., 2018). Second, the cultural practice lens stresses the role of cultural scripts and norms and the existence of systems for enforcing these, such as by attributing cultural capital to those who follow dominant expectations. For example, Nasir and colleagues (2008) discussed potential conflicts between the communication norms that are valued in a mathematics classroom-such as expressing confidence rather than humility or challenging peers' and even the teacher's mathematical ideas-and those that students may be comfortable with. Finally, in a subtle but important shift, the interactive (re)production lens highlights how cultural practices are dynamically and interactively (re)produced by participants rather than as characteristic of group membership (K. Gutiérrez \& Rogoff, 2003). Through this lens, the relevance of hip-hop pedagogies for a particular group of students would be determined by their participation in hip-hop practices rather than on their membership in a group (i.e., because they are Black youth). 
Cultural Mechanism \#1: Mismatch. Researchers who adopted cultural perspectives in the reviewed literature also assumed one of three mechanisms for the (re)production of marginalization in mathematics classrooms, although there was no clear correlation between how culture was operationalized and which cultural mechanism was assumed. The first approach claimed that marginalization occurs when school culture and students' culture are mismatched, because it is more difficult to learn in an unfamiliar culture. For example, given that U.S. public schools typically reflect White, middle-class norms, students who are unaccustomed to this culture may feel uncomfortable with expectations such as working silently and independently or making direct eye contact with authority figures (e.g., Delpit, 1988). Alternately, students may not recognize references in the curriculum (such as in word problems; see Jackson et al., 2013), they may not recognize the identities made available to them in school culture (Cobb \& Hodge, 2011), or they may feel disengaged as a result of this cultural disconnect (Parker et al., 2017; Turner et al., 2009; Young et al., 2018). This account implies that addressing marginalization requires bringing students' culture and school culture into closer alignment, either by explicitly teaching students the rules and norms of school culture (e.g., code-switching) or adjusting school culture to be more familiar to students (e.g., culturally responsive teaching; recognizing students' cultural and linguistic capital). It does not, however, address the possibility that students who have learned school culture may nevertheless continue to be marginalized.

Cultural Mechanism \#2: Privilege. A closely related but slightly more critical approach suggested that marginalization occurs when school culture is privileged over students' culture. Both of these approaches are based on the premise of a mismatch between school culture and students' culture, but this second approach emphasized a hierarchy of cultures, where school culture is taken to be more valuable than students' culture, or where students' culture is seen as deficient compared to school culture, rather than simply different. Difference, especially deviance from societal norms, often becomes taken as deficit (McDermott \& Varenne, 1995). This approach implies interventions for 
addressing marginalization that may look similar on the surface to those described above, such as drawing on students' funds of knowledge to show that students' culture is in fact welcome in school, but requires a deeper axiological shift as well. Disrupting marginalization, when marginalization is due to the privileging of school culture over students' culture, calls for not just acknowledging students' culture but also for recognizing and disrupting the association between particular cultural practices and power (Nasir et al., 2008).

Cultural Mechanism \#3: Inherent Exclusion. The third approach that appeared in research drawing on the cultural perspective argued that marginalization occurs because the culture of school mathematics in the U.S. is inherently marginalizing. Bishop (1990) wrote that the culture of mathematics education in the U.S. upholds Western values such as rationalism, deductive reasoning, objectivity, and individual control over the environment, so students can only succeed by exemplifying these values. Boaler (2002), Horn (2010), Louie (2017), Schoenfeld (1988) and others emphasize that mathematical activity in U.S. mathematics classrooms is often narrowly defined as requiring a single right answer that has been predetermined by an authority figure, such as a teacher or textbook, and can only be found by memorizing and applying rote procedures. Louie (2017) highlights the way these conditions create cultures of exclusion, positioning students who are fast calculators or who excel through rote practice as preternaturally "gifted." If the culture of school mathematics is inherently marginalizing, as this approach suggests, then addressing the ongoing (re)production of marginalization necessitates a significant rethinking of how mathematics is taught in school, including (but not limited to) the way content is introduced, how teachers and students interact, and how students are assessed and placed in courses.

Political Perspectives. Finally, the political perspective on marginalization in mathematics classrooms focuses on the distribution of resources and power, and identifies hegemonic ideologiessystems of ideas that explain the dominance of the status quo and mobilize people in its service-as 
mechanisms for maintaining those distributions. Researchers adopting the political perspective claim that mathematics classrooms are a site for the reproduction of hegemonic ideologies that function to stratify people and consolidate hierarchies of power. For example, ideologies about the unquestioned primacy of English in the United States (Civil, 2014; Zavala, 2017), the existence of "smartness" (Leonardo \& Broderick, 2011), and White supremacy (Battey \& Leyva, 2016), to name just a few, operate within mathematics classrooms to marginalize students on the basis of language, ability, and race, respectively. From a political perspective, then, addressing the (re)production of marginalization requires interventions that extend beyond the mathematics classroom and into both political institutions, where decisions about distributing resources and power are often made, and the hearts and minds of those who, knowingly or unknowingly, internalize, transmit, and enforce marginalizing ideologies.

One study in the selected articles did take seriously a biological perspective in explaining marginalization, offering as an explanation for girls' marginalization that they have less innate ability than boys (Iwu \& Azoro, 2017). This biological approach, which argues that students are marginalized on the basis of genetic and/or inherited traits, characterized previous generations of education research, but has now been discredited (Damarin \& Erchick, 2010). Nonetheless, it would be irresponsible for mathematics education researchers to ignore the long shadow cast by the historical dominance of biological explanations. In some spaces, discourses of inferiority persist, effectively blaming students for their own marginalization and naturalizing it as a consequence of essential, biological difference. By contrast, the aforementioned psychological, cultural, and political perspectives do not take marginalization as inevitable. However, they do suggest that marginalization has many roots and takes many forms, so we next survey the social categories identified as being central in delineating who is marginalized in mathematics classrooms in the article corpus. 


\section{Focal Social Categories: Who Gets Marginalized?}

After sorting the primary corpus in terms of which students' marginalization in K-20

mathematics classrooms was most documented, seven salient categories emerged: ability, class, culture, gender, language, race, and intersecting identities. We reviewed how marginalization was conceptualized by researchers in each category to examine whether marginalization in mathematics education is theorized to operate by different processes depending on which students are targeted, although, of course, not all students in any identity category will experience marginalization the same way or through the same processes. We did not find strong correlations between the disciplinary perspective that articles used to theorize the processes by which marginalization is (re)produced and the identity category that they focused on, which reflects the heterogeneity in how marginalization in mathematics education can be sensibly conceptualized and testifies to the complexity of the phenomenon. Given our press toward critical bifocality, we are not surprised that multiple marginalization processes can operate on different identity categories; indeed, in our view, it is important that scholars recognize the multi-level processes that operate in simultaneity to (re)produce marginalized mathematics learners.

As with our above review of discipline-based processes, the aim in this section is not to attempt a comprehensive analysis of the literature in each identity category. Instead, for the sake of both space and synthesis, we provide an overview of trends that emerged and illustrate them using examples from the reviewed categories. First, we discuss how conceptualizations of marginalization varied based on the scope of marginalization under study. Then, we turn to variations in whether they centered the political perspective or viewed it as a backdrop and relatedly, whether power and ideology served as direct mechanisms for marginalization or as underlying other mechanisms for marginalization. Finally, we conclude this section by examining what intersectionality theory can contribute to understanding how marginalization is understood in mathematics classrooms. 
Scope: Day-to-day vs. Systematic Marginalization. The reviewed research varied in whether they prioritized the day-to-day marginalization of children in classrooms or the role of mathematics education as a case of and contributor to the marginalization of entire groups of children across an identity category. For example, articles that foregrounded ability as the basis for students' marginalization in mathematics education tended to focus on how mechanisms such as ability grouping, teachers' low expectations, and student disaffection serve as sources of marginalization for students identified as low-ability or low-track (Boaler et al., 2000); how students' cognitive processing and the mediational tools available to them may be mismatched (Lewis, 2014); and how the forms of mathematical activity in classrooms constrain and construct students' mathematical abilities (Lambert, 2015). Likewise, articles in the primary corpus that foregrounded sex ${ }^{1}$ as the basis for marginalization also identified mechanisms operating at the daily level: innate abilities and family expectations (Iwu \& Azoro, 2017); cultural practices in STEM departments (Kahveci et al., 2008); and low expectations from teachers, low self-esteem of students, and a mismatch between students' interests and teachers' pedagogical choices (Frost \& Wiest, 2007). Theorizing marginalization at the level of day-to-day (re)production, as these articles do, both creates opportunities for individual teachers to engage in compensatory practices and leaves open the possibility that some mathematics classrooms can avoid marginalization students on the basis of ability or sex.

Gender-focused articles in the supplemental corpus, on the other hand, more often articulated a systematic marginalization of women and girls across mathematics education. Mendick (2005) and Hottinger (2016) argued that the culture of school mathematics is necessarily exclusionary because it is gendered masculine, even though some women and girls may navigate school mathematics successfully. Linking mathematics to rationality and rationality to masculinity marginalizes students who do not

\footnotetext{
${ }^{1}$ According to Leyva (2017), much of the research in mathematics education claiming to address gender in fact conflates sex with gender, simply comparing the performance of students identified as girls against students identified as boys. We found this to be true in the primary corpus as well.
} 
identify with conventional notions of masculinity, especially if they identify as women because women are often presumed to be irrational (Haraway, 1991). Theorizing marginalization across an entire identity category may, like theorizing day-to-day (re)production, suggest compensatory practices for individual teachers in mathematics classrooms, but also highlights the insufficiency of such micro-level interventions for addressing systematic marginalization. In other words, responding to day-to-day marginalization can only be a stopgap measure, so long as mathematics education remains emblematic of the patriarchal and misogynist society in which it is situated and as long as women and girls' success in mathematics is positioned as "a threat to masculine rationality and to the bourgeois and patriarchal power which it underpins" (Walkerdine, 1989, p. 276).

Although some reviewed articles prioritized day-to-day (re)production and others prioritized systems in their theorization of marginalization in mathematics classrooms, these two scopes are not mutually exclusive. In fact, several articles in both the ability and gender categories explicitly linked the day-to-day (re)production of marginalization in mathematics classrooms to systematic marginalization within mathematics education. For example, Yeh and colleagues (2020) draw on the work of Tan and Kastberg (2017) and other scholars who theorize ability as a cultural construct and as a set of ideologies related to maintaining existing hierarchies of advantage (Artiles, 2013; Leonardo \& Broderick, 2011; McDermott \& Varenne, 1995; Sleeter, 1987). They chronicle how an individual teacher challenges models of ability that pathologize individual students and instead recognizes dis/ability in mathematics education as a product of historical, political, and relational constructions. Leyva's (2017) review similarly identifies classroom practices - such as participation norms and power dynamics around authoring versus assisting with mathematical problem-solving-as cases of gendered discourses of masculinity. These examples suggest that moving forward, mathematics education researchers could do more to frame the day-to-day (re)production of marginalization in mathematics classrooms as a way to 
operationalize macro-level theorizations of systematic marginalization rather than addressing one or the other separately.

The Political Perspective: Center vs. Backdrop. Another trend was that the reviewed articles in some identity categories were more likely to take the political perspective as an organizing principle in theorizing marginalization, presenting marginalization in mathematics education as an inevitable consequence of marginalization in society more broadly. For example, articles that foregrounded classbased marginalization drew on political theory to describe economic stratification in society and then illustrated the role of mathematics education within those patterns: reproducing class structures in response to demands for "a skilled and educated workforce" (Stinson, 2004, p. 12), assigning value to students based on their potential for contributing to the economy rather than based on their humanity (Gutstein, 2009), and controlling access to mathematical learning opportunities based on students' familiarity with knowledges and linguistic capital that reflect the experiences of the upper and middle class (Walkerdine, 1990; Zevenbergen, 1996; Zevenbergen, 2003). Theorizing marginalization using the political perspective as an organizing principle centers the idea that mathematics education operates in the shadow of and is therefore not immune to forms and processes of marginalization pervasive across schooling and society.

By contrast, articles that foregrounded culture-based marginalization-however researchers operationalized culture-generally did not use the political perspective as an organizing principle, instead opting to emphasize cultural processes of marginalization. They did, however, often nod to the political perspective by attending to how unequal distributions of resources and power marginalize students whose cultures do not align with the culture of school mathematics, whether due to a mismatch between the culture of school mathematics and students' culture (Ares, 2008; Ebby et al., 2011; Parker et al., 2017), the privileging of the culture of school mathematics over students' culture (Bishop, 1990; d'Ambrosio, 1985; Francois \& Stathopoulou, 2012; Nasir et al., 2008; Young et al., 2018), 
or the culture of school mathematics as being inherently marginalizing due to its overly narrow conceptions of what counts as mathematics and who can be good at mathematics (Louie, 2017). Each of these articles observed that students who were more familiar with the culture of school mathematics were afforded greater access to mathematical learning opportunities and those who were less familiar were marginalized.

Villegas's (1988) work on cultural mismatch, however, provides a reminder that U.S. schooling as an institution preserves the status quo, and therefore cultural mismatch as an explanation for marginalization can only be understood within the context of social inequalities that are 1) created and sustained by the privileging of some cultures over others in order to 2) maintain hierarchies of power, with "minority" (Villegas's term) students at the bottom. By theorizing marginalization using the political perspective as a backdrop rather than as an organizing principle, this subset of researchers was able to more deeply investigate cultural processes of and solutions to marginalization, albeit potentially at the expense of examining ideological interventions that might affect how resources and power are distributed across society. These ideological interventions could complement cultural approaches by shaping the traits, practices, and forms of capital that are considered normative in mathematics across society, as well as by filtering into the consciousnesses of individual teachers and students.

Power and Ideology: Direct vs. Indirect Mechanisms. Across reviewed articles that took a political perspective to explaining marginalization in mathematics classrooms, some treated power dynamics and hegemonic ideologies as underlying psychological or cultural mechanisms for the (re)production of marginalization whereas others identified power and ideology as being directly responsible. Research foregrounding marginalization on the basis of race and language most clearly illustrated this trend. For example, Battey and Leyva (2016) explained that ideologies of white supremacy in mathematics classrooms marginalize students of color and maintain the purported superiority of White students through psychological mechanisms (such as students' identity and agency) 
and through cultural mechanisms (such as the characteristics and practices of school mathematics), but political ideas about who should have power lie at the root of these mechanisms. Other researchers discussed the history of racism and named patterns of racist oppression across institutions in the context of illustrating how the (re)production of existing power structures and use of ideological justifications underpin psychological or cultural mechanisms by which students are marginalized: students' mathematical identities (McGee, 2015); discrimination, low expectations, and opportunity gaps (Morvan, 2017); students' disconnection from mathematics curricula (Turner et al., 2009); a lack of care or deficit orientations from teachers (McKinney de Royston et al., 2017); and mismatched pedagogies and underresourced schools (Rubel, 2017) are all justified by racial ideologies. Similarly, articles foregrounding language-based marginalization situated multilingual students' need to learn a distinct mathematical register (Schleppegrell, 2007) and the practices of multiple language communities (Moschkovich, 2002) in the context of English being associated with power in the United States.

Alternately, other researchers argue that the ideologies associated with language and race themselves are directly responsible for the marginalization of students who are marked as inferior to others based on their home languages and racialized bodies (Flores \& Rosa, 2015; Macedo, 1991). From this view, simply changing the language of instruction fails to acknowledge the political significance of the "hegemony of English" (Zavala, 2017, p. 50; see also Civil, 2014); the characterization of English as the language of mathematics and authority in contrast to home languages as the language of solidarity marginalizes students who are not normatively fluent in English (Setati, 2005). Likewise, race-based deficit narratives about students of color (Adiredja, 2019) themselves produce marginalization, as do the ideological availability of "missionary" and "cannibal" positions for White teachers of Black students (Martin, 2007); the racial hierarchies in mathematics education that limit students' identities (Martin, 2009); the contribution of ongoing marginalization based on race to the racial projects that organize U.S. society (Martin, 2013); the deliberate maintenance of race-based marginalization to thwart Black 
liberation (Martin, 2019); the use of Whiteness as an ideology to justify the exclusion of people marked as non-White (Harris, 1993); and anti-Blackness as marking Black people as fundamentally ineligible for humanity and, by extension, education (Dumas, 2016).

Either approach-theorizing the existence of hegemonic ideologies to be indirectly or directly responsible for the marginalization of students in mathematics classrooms-makes explicit the relationship between the daily (re)production of marginalization in mathematics classrooms and the way that the present distribution of resources across groups of people is concentrated through the creation and conservation of hierarchies of power. It is worth noting that these approaches were most apparent in articles foregrounding race and language, and we wonder how researchers studying other identity categories might theorize the directness or indirectness of ideology in (re)producing marginalization along other identity axes.

Intersecting Identities, Intersecting Theorizations. Finally, the plurality of articles in the primary corpus focused on how students' multiple identities made them targets of marginalization in mathematics classrooms. Although some of these articles simply named more than one social category as the focus of their research (most commonly race and gender), others drew heavily on intersectionality as a theory rooted in the work of women of color scholars such as Crenshaw (1991) and Collins and Bilge (2016). Grounded in Black Feminist Theory, intersectionality theory does not merely label people as members of multiple social identity groups. Instead, it emphasizes how social identity groups are differently subordinated within different systems of oppression, and therefore how individuals' multiplicitous social identity markers make them vulnerable to marginalization in multiplicative rather than additive ways; for example, Black women and White women experience patriarchy differently, just as Black women and Black men experience racism differently. What matters to scholars who use intersectionality theory are the consequences of social identity categories as they intersect with one another, not the mere existence of said categories. 
Some scholars turn to historical legacies to understand intersectional oppression. For example, Kitchen and colleagues (2016) cited the historical denial of opportunity to students on the basis of culture, language, gender, and class as the reason for marginalization in mathematics education. Others extend historical analyses to the production of social structures that maintain systems of power. In this vein, Rochelle Gutiérrez (2002) and Bullock (2018) delved further into how structures of mathematics education embody systemic oppression against multiple identity groups, surveying cultural and political mechanisms for marginalization, in addition to acknowledging it as a legacy of historical discrimination. Other articles focused on the dominant ideologies that mark some students as inferior on the basis of social categories and thus, treated unjustly on the basis of multiple social categories: Rochelle Gutiérrez (2013) articulated the low status ascribed to “Black, Latin@, American Indian, and low income" students (p. 7); Leyva (2016) claimed that mathematics serves as a "source of power that structures a hierarchy of ability aligned with society's inequitable opportunities" for Latin@ women (p. 89); Frank (2018) narrated the consequences of a "hierarchy of achievement" (p. 146) in mathematics for Black students of a Black male teacher, and Langer-Osuna (2016) traced the reproduction of power relations within a mathematics classroom based on "broader society's intersecting racialized, gendered, and classed hierarchies" (p. 53). By contrast, Ireland and colleagues (2018) reviewed studies examining the "psychological meaning of membership in oppressed groups" (p. 230) for Black women and girls through constructs such as identity, persistence, achievement, and perceptions. Finally, some scholars looked at specific cultural practices within mathematics classrooms with an intersectional lens to understand how they operate to marginalize students: Leonard and colleagues (2010) and Joseph and colleagues (2017) described school mathematics practices that are inherently exclusionary on the basis of race and gender, with the latter article also stressing how the political ideology of White supremacy creates unwelcoming environments specifically for Black women and girls. 
As with research foregrounding single social identity markers, articles centering how students are marginalized in mathematics classrooms based on their intersecting identities typically situated their conclusions in the context of systems of oppression that reach across institutions and contexts. This trend, across the reviewed articles, suggests that although each disciplinary perspective contributes uniquely to theorizing marginalization in mathematics classrooms, the political perspective provides an important backdrop to understanding and addressing marginalization and cannot be ignored. Just as intersecting identities shape who experiences marginalization and in what forms, the intersection of disciplinary traditions with focal social categories provides theories of marginalization that illuminate how marginalization is (re)produced and therefore, how its (re)production might be interrupted. To tie these studies together, we now turn to some broader claims about how marginalization happens.

\section{Theorizing Marginalization in Mathematics Classrooms}

The articles reviewed for this paper attempted to explain why and how particular groups of students are marginalized in $\mathrm{K}-20$ mathematics classrooms, in addition to simply documenting its existence or proposing interventions to address it. They demonstrate diverse underlying assumptions about how marginalization is (re)produced, rooted in different disciplinary traditions, and vary in terms of whose marginalization they document. Reading across the identified mechanisms of marginalization in these articles, we claim that compelling theories of marginalization in mathematics classrooms are characterized by several shared understandings: 1) marginalization is neither new nor not normal; 2) the means of marginalization are both material and ideological; and 3) there are both individual and structural contributors to marginalization. In the remainder of this section, we claim that these shared understandings illustrate the complexity of marginalization in mathematics classrooms as a phenomenon. In the next section, we note that research addressing marginalization, then, must be similarly complex. Together, we take these claims as pointing to the need for critical bifocality (Weis \& Fine, 2012) in studying marginalization in mathematics classrooms. 
Marginalization is neither new nor not normal. Almost universally, the reviewed articles acknowledge that the forms of mathematical marginalization under study were continuations of historical marginalization. These historical antecedents may operate directly, as through the creation of an "impoverished educational system... [for] low-income students and students of color" (Kitchen et al., 2016, p. 19), or less directly, as by normalizing savioristic "missionary frames" for White teachers working with students of color (Martin, 2007). As a result, marginalization is situated in time. The processes that produce marginalization in mathematics classrooms are never newly generated in the moment, but rather, reproduce forms of marginalization that existed long before any specific classroom, teacher, or group of students comes together.

These historical antecedents matter. For example, mathematics teachers' implicit biases against girls comes from somewhere; what counts as mathematical vocabulary comes from somewhere; the designation of particular interactional styles as "appropriate" for mathematics classrooms comes from somewhere. Therefore, generative theories of marginalization account for both the history and reproduction of marginalization instead of treating instances of marginalization as novel, regardless of the disciplinary perspective they adopt. History is a fundamental part of the circuits through which mathematical marginalization happens across timescales.

Articles taking a political perspective argue that marginalization is not only not new, but it is also normal. Examining marginalization across societal institutions, including mathematics classrooms, makes apparent that the same groups of people are targeted over and over: those who do not belong to the dominant ability, class, cultural, gender, language, or racial groups. Critical scholars (e.g., Delgado \& Stefancic, 1995; Leonardo \& Broderick, 2011; Martin, 2019; Flores \& Rosa, 2015) contend that this is not an accident given the unequal distribution of power and resources in society; those who have more are interested in maintaining their positions of privilege and dominance and do so by marginalizing others. 
Of course, there are inevitably instances of one-off marginalization in classrooms, where even a student marked by dominant social identities or who has never felt marginalized before might be excluded or made to feel unwelcome; Kotsoupoulos (2014) and Lambert (2015), for example, describe classroom interactions and pedagogies by which students are positioned as more or less mathematically capable, which could happen to any student regardless of demographics. Langer-Osuna (2015) reminds us, however, that positioning processes more often than not reproduce existing power relations, so that students who are already at the bottom of social hierarchies are more likely to be marginalized. Because the marginalization of some people has been normalized in society over centuries of human history, conducting mathematics education research with a business-as-usual approach will continue to perpetuate marginalization, rather than operate neutrally. In fact, marginalization is to be expected in mathematics classrooms, unless the status quo is somehow in flux. Therefore, those who seek to mitigate or eliminate marginalization in $\mathrm{K}-20$ mathematics classrooms are faced with the challenge of actively disrupting longstanding and widespread patterns, thus requiring a coordination of macro-, meso-, and micro-analyses.

Marginalization operates through material and ideological mechanisms. Some of the reviewed articles defined marginalization as the denial, to particular groups of people, of access to resources. For example, achievement tracking is a common practice in mathematics education, and students of color are more likely to be tracked out of college-preparatory and higher-level courses and into remedial mathematics classes (Joseph et al., 2017; Martin, 2013; Morvan, 2017). This material dispossession prevents targeted people from having the same opportunities as privileged people. Other articles highlight an immaterial but no less consequential form of dispossession: particular groups of people are valued less than and considered inferior to others (Battey \& Leyva, 2016; Leyva, 2017; Setati, 2005). Sometimes this ideological marginalization is based on characteristics that most people would recognize as illogical: the color of someone's skin, or the wealth of someone's parent. Sometimes, however, this 
ideological marginalization is based on more subtle characteristics that may appear to be justifiable but nonetheless perpetuate unjust marginalization, such as hardworkingness, memory capacity, or proclivity for deductive reasoning (Bishop, 1990; Louie, 2017). Mathematics education not only recruits societal narratives about superiority and worthiness, but also carries its own: Martin (2009) describes how the racial hierarchy in mathematics education disenfranchises Black students; Gutstein (2009) details producerist ideologies that result in "creaming the crop" (p. 154) by only educating the students deemed most mathematically adept; and Adiredja (2019) demonstrates how Latina mathematics majors could be interpreted as either struggling and confused or engaged in mathematical sensemaking, depending on whether deficit or anti-deficit narratives are used.

The material and ideological mechanisms of marginalization in mathematics classrooms are mutually reinforcing. For example, believing that particular groups of students cannot or will not be able to take advantage of opportunities such as Advanced Placement courses (ideological), perhaps due to wrongly believing that they or their families do not value education, becomes a reason to track them into remedial courses (material). Students excluded from opportunities to explore mathematical ideas using their own language and resources (material) may then be seen as uncreative or incapable of tackling rich problems (ideological). Therefore, interventions aimed at mitigating or eliminating the (re)production of marginalization need to target both material and ideological mechanisms: both the concrete resources and opportunities that are denied to particular groups of students as well as the narratives that circulate to justify such denial.

Marginalization operates through individual and structural mechanisms. Finally, the reviewed articles shared an acknowledgment that what individuals do, including marginalizing others or becoming marginalized themselves, is neither entirely up to them (due to the role of socialization, norms, or ideologies) nor entirely predetermined (because individuals always have the agency to comply or resist). Therefore, accurately theorizing marginalization requires examining both the systems that (re)produce 
marginalization and how individuals enact, perpetuate, resist, or otherwise respond to the mechanisms of marginalization. In other words, marginalization happens on an individual basis, such as when individual teachers express biases or individual students feel unwelcome in a particular classroom, but divorcing individual interactions and experiences from structures of oppression ignores how structures and people's lives interact (Weis \& Fine, 2012). As Gholson (2019) describes, citing (Frye, 1983), seeing oppression is like looking at a bird in a cage: from very close in, an observer may miss the wires and the bird may seem free; but looking from further out, the wires that so obviously keep the bird in place are unmistakable.

For example, an intervention like coaching mathematics teachers to build inclusive classrooms may protect students from some forms of discrimination, but does not in and of itself address structural pressures that create exclusionary learning environments, such as the use of test scores to determine school funding, which often leads teachers to divert their attention to "bubble kids" at the expense of higher- or lower-performing students (Horn et al., 2015). An intervention that shows students the educational and career opportunities afforded by STEM success may increase their extrinsic motivation to learn mathematics, but it does not address structural reasons students may be deterred or discouraged from such opportunities, such as explicit gatekeeping in university departments (Ong et al., 2017) or the high cost of college tuition (Goldrick-Rab, 2006). For this reason, we return to our main takeaway from this literature review: understanding and addressing marginalization in K-20 mathematics classrooms requires critical bifocality —attending to both individuals and structures rather than focusing solely on one or the other-to "document the implications of far-away policies and upclose decisions by, for, and against the interests of privileged and marginalized youth" (Weis \& Fine, 2012, p. 196). 


\section{Discussion and Implications}

Examining research on marginalization in $\mathrm{K}-20$ mathematics classrooms across a range of disciplinary perspectives and focal social categories reveals great heterogeneity in how researchers theorize the (re)production of marginalization, drawing as they do on psychological, cultural, and political perspectives to frame the processes by which students become marginalized, and underscoring how students identified within different social categories experience these processes. Our review suggests that marginalization is a complex phenomenon that is neither new nor not normal, both material and ideological, and both individual and structural. Consequently, addressing marginalization in K-20 mathematics classrooms requires complex and multifaceted responses. In this section, we draw on Weis and Fine's (2012) notion of critical bifocality to elaborate what that might look like in mathematics education research and pose some questions that remain.

\section{Critical Bifocality}

The recurrence of political theorizations of marginalization in our review, whether foregrounded as the primary mechanisms by which students are marginalized in mathematics classrooms or backgrounded as the context in which marginalization in mathematics classrooms must be situated, points to the centrality of power, ideology, and social structures in organizing students' experiences. Toggling between such macro-scale factors and the micro-scale of students' day-to-day lived experiences of marginalization in mathematics classrooms is challenging, and we recommend Weis and Fine's (2012) frame of critical bifocality as a valuable way to conceptualize the relationship between them. First, critical bifocality highlights the inextricability of sociopolitical formations from individual lives: "structures produce lives at the same time as lives across the social class spectrum produce, reproduce, and, at times, contest these same social/economic structures" (Weis \& Fine, 2012, p. 175). Second, critical bifocality's attention to lives demands a close-up, deeply humanizing examination of how students experience marginalization as individuals, not just as members of groups. 
Not all students of color experience Whiteness in mathematics the same way, and not all students who identify as women experience the rational masculinity of mathematics the same way, as Leyva (2016) and Frank (2018) illustrate for Latin@ college women and Black male teachers, respectively, in this review. However, critical bifocality also reminds us that, as we mentioned earlier, members of some groups have historically been and continue to be targeted for marginalization more so than others due to the macro-structures-such as racism--that organize our society. Therefore, it is important to attend to students' identities as members of social groups, while also considering group identities that are marginalized but have not yet been well-documented in mathematics education research (e.g., religious identities; unhoused students). Rather than serving to essentialize or assume the experiences of students on the basis of how they are seen, then, attending to students' identities as marked by social categories is "most powerful for deciphering systems that structure the everyday conditions of individuals" (Gholson, 2019, p. 416), in tandem with analyses of how individuals inhabit and contest those structures. Next, we turn to examples of how critical bifocality currently manifests in mathematics education research and consider further opportunities for its use in framing future research.

\section{Critical Bifocality in Mathematics Education Research}

You can love what you see in the mirror, but you can't self-esteem your way out of the way the world treats you.

- Gabrielle Union, We're Going To Need More Wine

Like much thinking in U.S. education, mathematics education research tends to focus on individuals as the locus of intervention. For example, to address marginalization in K-20 mathematics classrooms, researchers might design programs to influence students' feelings of competence and belonging; teachers' attitudes and expectations of their students; teachers' noticing of particular mathematical practices or valuing of student thinking; or teachers' sociopolitical knowledge. Because they target individuals who are easily accessed within classrooms and schools, these interventions often 
have clear, measurable objectives, can be implemented within defined and relatively short time periods, and require comparatively few resources (e.g. a professional development facilitator; pre- and postintervention metrics). As a result, such interventions can be very attractive to researchers, practitioners, and policymakers interested in addressing marginalization in K-20 mathematics education, while also finding congruence with dominant cultural logics of individualism. Not only do these approaches have strong ecological validity in U.S. schools, organized around individual teachers and classrooms (Lortie, 1970), but also, providing marginalized students with increased access and mathematical learning opportunities, or bolstering their sense of identity and belonging, matters immediately for the millions of students currently sitting in mathematics classrooms. After all, practitioners eager to address abilitybased marginalization may not be able to single-handedly change hegemonic ideas about who is smart in society at large, but they certainly can make pedagogical choices that value different forms of mathematical activity and mathematical ability within their classrooms (Horn, 2017).

That said, focusing on individual-level change as a means for minimizing marginalization has several limitations. First, adopting this perspective may imply that the problem is with individual students and teachers, rather than with the structures and systems that (re)produce marginalization (see, for example, Boaler's (2002) critique of Carol Dweck's growth mindset interventions). This implication easily slips into deficit views of student resources and student resilience, suggesting that perhaps students are marginalized because they have failed to imagine themselves as mathematicians, or because they have not tried hard enough to ignore exclusionary signals from their teacher and/or peers, or because it has not occurred to them to advocate for themselves. Likewise, teacher-focused interventions frequently make assumptions about who the "default" teacher is: programs aiming to boost teachers' racial consciousness, for example, are often designed for White middle-class teachers and overlook the lived experiences of teachers of color who are also sitting in the same university courses (Brown, 2014). Relatedly, interventions focused on changing teachers may "overemphasize 
teacher agency and overlook ways in which such agency is structured by the norms of schools as societal institutions" (Chazan et al., 2016, p. 1079), blaming teachers for circumstances beyond their control or for failing to triumph over the many social, institutional, and ideological forces pressuring them to remain complicit in marginalization. Second, relying solely on individual-level interventions requires acting as if "good teachers and schools alone can narrow achievement gaps, and that the demise of segmented class and racial structures will inevitably follow" (Weis \& Fine, 2012, p. 173); the endurance of oppression across history provides little evidence that this theory of change is valid.

Relatedly and more importantly, individual-level interventions may mitigate harm in a non-ideal world by preparing students to face difficult situations by developing coping skills or building teachers' repertoires of inclusive instructional pedagogies, but do not in and of themselves challenge systemic racism, sexism, and other forms of oppression. Students who have not yet experienced the interventions will continue to be targeted for marginalization in mathematics classrooms, and teachers who have not yet experienced interventions will continue to perpetuate marginalization. Furthermore, such interventions may inadvertently recreate new hierarchies of ability; for example, privileging forms of mathematics that are not currently privileged may position students as mathematically able who would not otherwise be positioned that way, but nonetheless privileges some ways of doing mathematics and some students over others and marginalizes those who do not fit.

Of course, these risks do not mean that individual-level interventions are futile, but rather, that their scope must be expanded to consider structural influences as well. For example, a racial bias reduction exercise alone may reduce mathematics teachers' endorsement of the specific stereotypes discussed; linking those stereotypes to the ideological context of racial projects that create and enforce hierarchies of status and power across contexts (Martin, 2013), however, could illuminate for teachers how such stereotypes - as well as stereotypes and narratives that were not named in that particular workshop-serve to maintain existing patterns of dominance and marginalization. Researchers or 
administrators who approach such bias-reduction programming through the lens of critical bifocality would recognize that it is easier for teachers to default to commonsensical ways of thinking and acting that (re)produce marginalization, due to cultural norms and scripts and the internalization of deficit ideologies, than to challenge them (Kumashiro, 2004). As a result, they might also modify the conditions under which teachers work to make the school environment more conducive to disrupting patterns of marginalization: reducing teacher workload, giving them opportunities to reflect and consult with colleagues, increasing teacher compensation, employing accountability measures that are more humanizing than standardized test scores, acknowledging and developing teachers' professional judgment rather than diminishing their autonomy, and so on (see, e.g., Diamond, Randolph \& Spillane, 2004).

It remains to be determined how exactly researchers, practitioners, and policymakers can contribute to making visible and then shifting marginalizing ideologies, such as those that link particular forms of mathematical competence to the national rhetoric around students' deservingness of opportunity or their potential for contribution to the economy, so often used to justify calls for improving STEM education (Gutstein, 2009). However, scholars have chronicled how dominant ideologies shift over time (e.g., Fairclough, 2015; Omi \& Winant, 2014), and some are beginning to study deliberate efforts to shift such ideologies within mathematics education (Bannister, 2015). Additionally, mathematics education researchers are increasingly focusing on the dynamics of reproduction and resistance in mathematics classrooms as students and teachers demonstrate agency in contesting or perpetuating forms of systemic marginalization (e.g., Esmonde \& Langer-Osuna, 2013; Hand, 2010; Philip, Olivares-Pasillas \& Rocha, 2016; Sengupta-Irving, Tunney, \& Macias, in press). Further work along these lines could consider, to provide just one question we wondered about after reading the reviewed articles, how particular pedagogical practices (such as homework policies or requirements to use specific 
technological tools) or contextual conditions (such as curricular choices or assessment formats) marginalize students' ways of being mathematical rooted in their socioeconomic class.

\section{Challenges from Critical Bifocality}

We have argued that critical bifocality is crucial to the design and implementation of research that can meaningfully address marginalization in K-20 mathematics classrooms and offered examples of existing, in progress, and possible research accordingly. As with any lens, however, and as is hopefully obvious by this point, critical bifocality is not a silver bullet solution given the complexity and entrenched nature of marginalization in mathematics classrooms and across society, and many challenges remain. We encourage our fellow mathematics education researchers to join us in engaging the following questions:

1. How specific must solutions to marginalization be? Many of the theories of marginalization reviewed here suggest that each student and each classroom of students are different, because they are subject to a different set of individual, cultural, and political histories and forces. In other words, the way that a Black fifth-grader in Atlanta experiences marginalization is not the same as the way an Indigenous eighthgrader in South Dakota experiences marginalization. Yet, educational interventions are often judged on their ability to scale: the same curricula are designated for use across an entire state; the same teacher professional development is mandated for teachers across grade levels; a lesson plan template or groupwork structure is recommended for teaching students all types of mathematical ideas. This preference for scalability and generalizability may be efficient, but depends on the assumption that the influence of interventions is transferable: a teacher who improves at noticing participation patterns or becomes more knowledgeable about the history of racism in STEM will be able to leverage this new learning, even if they change schools or subjects; a student who 
becomes aware of and able to protect oneself against stereotype threat will be able to do so in all future mathematics classes and work environments. Scale is useless without attention to how meaning is preserved (K. Gutiérrez \& Jurow, 2016), and counterhegemonic meanings seldom travel well. It may well be that the rush to scale up is a misguided goal, since our critical bifocality lens suggests that there may be macrolevel marginalization processes that are invisible at the micro- or meso-levels.

2. How can ideologies be shifted at scale to ameliorate marginalization? Although specific interventions are unlikely to scale, the dominant ideologies that marginalize students in K-20 mathematics classrooms nevertheless create narratives-such as those about smartness or success - are so widely accepted as to be commonsensical. What does it take to shift our collective common sense about what it means for mathematics education to be meaningful for all students, especially those who have historically been and continue to be most marginalized? Does mathematics education need a truth and reconciliation process with its own problematic history?

3. How will systematic change happen given that mobilizing the collective will to change would be a threat to entrenched power structures? Those who benefit from the status quo-the typically White, middle-class students who benefit from the continued marginalization of particular students in $\mathrm{K}-20$ mathematics classrooms; the business and philanthropic interests who profit from educational inequality (Rooks, 2017)-have an active interest in preserving mathematics education as it currently exists, and, by the nature of their advantage are positioned with the power to resist change (see, for example, Rosen, 2001). 


\section{Conclusion}

This paper set out to identify theories of marginalization in order to understand the processes by which students have been and continue to be marginalized in mathematics classrooms, rather than simply labeling some groups of students as being marginalized based on their social identity markers. Doing so contributes insights into how to effectively address marginalization and avoid interventions that may at best, create "sweet, quiet spots of refuge" (Weis \& Fine, 2012, p. 175) for some students while ignoring others, or at worst, actively perpetuate marginalization. Through a review of literature on marginalization in mathematics education research and the identification of related foundational articles that articulate the theoretical assumptions underlying empirical work, we determined that mathematics education researchers draw on a variety of disciplinary traditions for theorizing how marginalization happens, frequently adopting psychological, cultural, or political perspectives, and foreground a range of social categories. From examining the similarities and differences between these theories of marginalization, we argued that 1) marginalization is neither new nor not normal; 2) the means of marginalization are both material and ideological; and 3) there are both individual and structural contributors to marginalization, suggesting a need to approach mathematics education research using critical bifocality (Weis \& Fine, 2012) to address the multiple scales at which marginalization takes place.

In short, researchers, practitioners, and policymakers concerned with marginalization in K-20 mathematics classrooms must grapple with the complexity of remedying marginalization and the consequent multiplicity of solutions required; the tension between local and generalizable solutions; and whether the intention of any intervention is to arrest the ongoing (re)production of marginalization, to mitigate its effects on students, or to imagine alternate realities in which marginalization is no longer endemic to mathematics education. The designs, methods, and epistemologies of those seeking to address marginalization must acknowledge the multiple scales at which these processes co-occur and 
reinforce each other if we are to create more inclusive, humanizing, and hopeful mathematics classrooms for students.

We close with a final provocation. Those disquieted by the (re)production of marginalization in K-20 mathematics classrooms may seek strategies for resisting its unremitting perpetuation, for mitigating its effects on students currently experiencing its consequences, or for eliminating further and future marginalization. Recently, however, mathematics education researchers have begun to call for even more revolutionary action. For example, a radical reimagination of mathematics education might move beyond dichotomous perceptions of conventional mathematics education and better forms of mathematics education to consider living and performing mathematx as a political statement that recenters what has traditionally been lost (R. Gutiérrez, 2017). Alternatively, mathematics education may need to be outright refused by those who "believe in the humanity of Black people" (Martin, 2019, p. 471). It is conceivable that interventions for mitigating the consequences of marginalization in mathematics education or for disrupting its (re)production, such as those described above, could be orthogonal to or even contradict more revolutionary goals. Helping some marginalized students access the culture of mathematical power (cf. Delpit, 1988) while keeping dominant power structures in place, for instance, may only enhance the plausibility of meritocratic myths that offer a distorted sense of possibility without truly undoing broader structural inequities. Aiming for radical reimagination or refusal, rather than harm reduction or interrupting the (re)production of marginalization, may promise more sweeping change, but may be far more challenging to conceptualize and implement, and thus may not be timely for the millions of students currently being marginalized in their K-20 mathematics classrooms. In that case, where should we begin? 


\section{References}

Adiredja, A. P. (2019). Anti-deficit narratives: Engaging the politics of research on mathematical sense making. Journal for Research in Mathematics Education, 50(4), 401.

* Ares, N. (2008). Cultural practices in networked classroom learning environments. International Journal of Computer-Supported Collaborative Learning, 3(3), 301-326.

Artiles, A. J. (2013). Untangling the racialization of disabilities: An intersectionality critique across disability models. Du Bois Review: Social Science Research on Race, 10(2), 329-347.

Bannister, N. A. (2015). Reframing practice: Teacher learning through interactions in a collaborative group. Journal of the Learning Sciences, 24(3), 347-372.

* Battey, D. \& Leyva, L. A. (2016). A framework for understanding Whiteness in mathematics education. Journal of Urban Mathematics Education, 9(2), 49-80.

Bishop, A. J. (1990). Western mathematics: the secret weapon of cultural imperialism. Race \& Class, $32(2), 51-65$.

Boaler, J. (2002). Paying the price for "sugar and spice": Shifting the analytical lens in equity research. Mathematical Thinking and Learning, 4(2\&3), 127-144.

Boaler, J., \& Greeno, J. G. (2000). Identity, agency and knowing in mathematics worlds. In J. Boaler (Ed.), Multiple Perspectives on Mathematics Teaching \& Learning. Westport, CT: Greenwood Press.

Boaler, J., Wiliam, D., \& Brown, M. (2000). Students' experiences of ability grouping-disaffection, polarisation and the construction of failure. British Educational Research Journal, 26(5), 631-648.

* Bullock, E. C. (2018). Intersectional analysis in critical mathematics education research: A response to figure hiding. Review of Research in Education, 42(1), 122-145.

Chazan, D., Herbst, P. G., \& Clark, L. M. (2016). Research on the teaching of mathematics: A call to theorize the role of society and schooling in mathematics instruction. In D. H. Gitomer \& C. A. 
Bell (Eds.), Handbook of research on teaching (5th ed.). Washington, DC: American Educational Research Association.

* Civil, M. (2014). Why should mathematics educators learn from and about Latina/o students' in-school and out-of-school experiences? Journal of Urban Mathematics Education, 7(2), 9-20.

Cobb, P., \& Hodge, L. L. (2011). Culture, identity, and equity in the mathematics classroom. In E. Yackel (Ed.), A Journey in Mathematics Education Research (Vol. 48, pp. 179-195).

Collins, P. H., \& Bilge, S. (2016). Intersectionality. Malden, MA: Polity Press.

Crenshaw, K. W. (1991). Mapping the margins: Intersectionality, identity politics, and violence against women of color. Stanford Law Review, 43(6), 1241-1299.

d'Ambrosio, U. (1985). Ethnomathematics and its place in the history of mathematics. For the Learning of Mathematics, 5(1), 44-48.

Damarin, S., \& Erchick, D. B. (2010). Toward clarifying the meanings of "gender" in mathematics education research. Journal for Research in Mathematics Education, 41(4), 310-323.

* de Araujo, Z., Roberts, S. A., Willey, C. \& Zahner, W. (2018). English learners in K-12 mathematics education: A review of the literature. Review of Educational Research, 88(6), 879-919.

Delgado, R., \& Stefancic, J. (1995). Critical race theory: An introduction. New York, NY: New York University Press.

Delpit, L. (1988). The silenced dialogue: Power and pedagogy in educating other people's children. Harvard Educational Review, 58(3), 280-298.

Diamond, J. B., Randolph, A., \& Spillane, J. P. (2004). Teachers' expectations and sense of responsibility for student learning: The importance of race, class, and organizational habitus. Anthropology \& Education Quarterly, 35(1), 75-98.

Dumas, M. J. (2016). Against the dark: Antiblackness in education policy and discourse. Theory Into Practice, 55(1), 11-19. 
* Ebby, C., Lim, V., Reinke, L., Remillard, J., Magee, E., Hoe, N., \& Cyrus, M. (2011). Community based mathematics project: Conceptualizing access through locally relevant mathematics curricula. Penn GSE Perspectives on Urban Education, 8(2), 11-18.

Esmonde, I., \& Langer-Osuna, J. M. (2013). Power in numbers: Student participation in mathematical discussions in heterogeneous spaces. Journal for Research in Mathematics Education, 44(1), 288-315.

Fairclough, N. (2015). Language and power. New York, NY: Routledge. (Original work published 1989)

Flores, N., \& Rosa, J. (2015). Undoing appropriateness: Raciolinguistic ideologies and language diversity in education. Harvard Educational Review, 85(2), 149-171.

* Francois, K. \& Stathopoulou, C. (2012). In-between critical mathematics education and ethnomathematics: A philosophical reflection and an empirical case of a Romany students' group mathematics education. Journal for Critical Education Policy Studies, 10(1), 234-247.

* Frank, T. J. (2018). Teaching our kids: Unpacking an African-American mathematics teacher's understanding of mathematics identity. Journal for Multicultural Education, 12(2), 144-160.

* Frost, J. H. \& Wiest, L. R. (2007). Listening to the girls: Participant perceptions of the confidenceboosting aspects of a girls' summer mathematics and technology camp. Mathematics Educator, $17(2), 31-40$.

Gholson, M. L. (2019). Read me last: Constructing a scholarly catchment through a black feminist reading. Cognition and Instruction, 37(3), 414-421.

Goldrick-Rab, S. (2006). Following their every move: An investigation of social-class differences in college pathways. Sociology of Education, 79(1), 67-79.

Gutiérrez, K. D., \& Jurow, A. S. (2016). Social design experiments: Toward equity by design. Journal of the Learning Sciences, 25(4), 565-598. 
Gutiérrez, K. D., \& Rogoff, B. (2003). Cultural ways of learning: Individual traits or repertoires of practice. Educational Researcher, 32(5), 19-25.

* Gutiérrez, R. (2002). Enabling the practice of mathematics teachers in context: Toward a new equity research agenda. Mathematical Thinking and Learning, 4(2-3), 145-187.

Gutiérrez, R. (2010). The sociopolitical turn in mathematics education. Journal for Research in Mathematics Education, 44(1), 37-68.

* Gutiérrez, R. (2013). Why (urban) mathematics teachers need political knowledge. Journal of Urban Mathematics Education, 6(2), 7-19.

Gutiérrez, R. (2017). Living Mathematx: Towards a vision for the future. Philosophy of Mathematics Education Journal, 32, 1-34.

Gutiérrez, R. (2018). The need to rehumanize mathematics. In I. M. Goffney \& R. Gutiérrez (Eds.), Rehumanizing mathematics for Black, Indigenous, and Latinx students (pp. 1-10). Reston, VA: National Council of Teachers of Mathematics.

Gutstein, E. (2009). The politics of mathematics education in the United States: Dominant and counter agendas. In B. Greer, S. Mukhopadhyay, A. B. Powell, \& S. Nelson-Barber (Eds.), Culturally Responsive Mathematics Education (pp. 137-163). New York, NY: Routledge.

Hand, V. (2010). The co-construction of opposition in a low-track mathematics classroom. American Educational Research Journal, 47(1), 97-132.

Haraway, D. J. (1991). Situated knowledges: The science question in feminism and the privilege of partial perspective. In Simians, Cyborgs, and Women: The Reinvention of Nature (pp. 183-201). New York, NY: Routledge.

Harris, C. I. (1993). Whiteness as property. Harvard Law Review, 106(8), 1707-1791.

Horn, I. S. (2007). Fast kids, slow kids, lazy kids: Framing the mismatch problem in mathematics teachers' conversations. Journal of the Learning Sciences, 16(1), 37-79. 
Horn, I. S. (2010). Teaching replays, teaching rehearsals, and re-visions of practice: Learning from colleagues in a mathematics teacher community. Teachers College Record, 112(1), 225-259.

Horn, I. S., Kane, B. D., \& Wilson, J. (2015). Making sense of student performance data: data use logics and mathematics teachers' learning opportunities. American Educational Research Journal, 52(2), 208-242.

Hottinger, S. N. (2016). Inventing the mathematician: Gender, race, and our cultural understanding of mathematics. Albany, NY: State University of New York Press.

Inglis, M., \& Foster, C. (2018). Five decades of mathematics education research. Journal for Research in Mathematics Education, 49(4), 462-500.

* Ireland, D. T., Freeman, K. E., Winston-Proctor, C. E., DeLaine, K. D., McDonald Lowe, S., \& Woodson, K. M. (2018). (Un)hidden figures: A synthesis of research examining the intersectional experiences of Black women and girls in STEM education. Review of Research in Education, 42(1), 226-254.

* Iwu, R. U. \& Azoro, A. V. (2017). A study on the barriers to participation of females in science, mathematics and technology education in imo state the way forward. Educational Research and Reviews, 12(17), 832-838.

Jackson, K., Garrison, A., Wilson, J., Gibbons, L., \& Shahan, E. (2013). Exploring relationships between setting up complex tasks and opportunities to learn in concluding whole-class discussions in middle-grades mathematics instruction. Journal for Research in Mathematics Education, 44(4), $646-682$.

* Joseph, N. M., Hailu, M., \& Boston, D. (2017). Black women's and girls' persistence in the P-20 mathematics pipeline: Two decades of children, youth, and adult education research. Review of Research in Education, 41(1), 203-227.

* Kahveci, A., Southerland, S. A., \& Gilmer, P. J. (2008). From marginality to legitimate peripherality: Understanding the essential functions of a women's program. Science Education, 92(1), 33-64. 
Kennedy, M. (2007). Defining a literature. Educational Researcher, 36(3), 139-147.

* Kitchen, R, Ridder, S. A., \& Bolz, J. (2016). The legacy continues: "The test" and denying access to a challenging mathematics education for historically marginalized students. Journal of Mathematics Education at Teachers College, 7(1), 17-26.

* Kotsopoulos, D. (2014). The case of Mitchell's cube: Interactive and reflexive positioning during collaborative learning in mathematics. Mind, Culture, and Activity, 21(1), 34-52.

Kumashiro, K. K. (2004). Against common sense. New York, NY: Routledge.

Lambert, R. (2015). Constructing and resisting disability in mathematics classrooms: A case study exploring the impact of different pedagogies. Educational Studies in Mathematics, 89(1), 1-18.

* Langer-Osuna, J. (2015). Linear equations and rap battles: how students in a wired classroom utilized the computer as a resource to coordinate personal and mathematical positional identities in hybrid spaces. Mathematics Education Research Journal, 27(1), 51-64.

* Leonard, J., Brooks, W., Barnes-Johnson, J., \& Berry, R. Q. (2010). The nuances and complexities of teaching mathematics for cultural relevance and social justice. Journal of Teacher Education, 61(3), 261-270.

Leonardo, Z., \& Broderick, A. A. (2011). Smartness as property: A critical exploration of intersections between Whiteness and disability studies. Teachers College Record, 113(10), 2206-2232.

Lerman, S. (2000). The social turn in mathematics education research. In J. Boaler (Ed.), Multiple Perspectives on Mathematics Teaching \& Learning (pp. 19-44). Westport, CT: Greenwood Press.

Lewis, K. E. (2014). Difference not deficit: Reconceptualizing mathematical learning disabilities. Journal for Research in Mathematics Education, 45(3), 351-396.

* Leyva, L. A. (2016). An intersectional analysis of Latin@ college women's counter-stories in mathematics. Journal of Urban Mathematics Education, 9(2), 81-121. 
Leyva, L. A. (2017). Unpacking the male superiority myth and masculinization of mathematics at the intersections: A review of research on gender in mathematics education. Journal for Research in Mathematics Education, 48(4), 397.

Louie, N. L. (2017). The culture of exclusion in mathematics education and its persistence in equityoriented teaching. Journal for Research in Mathematics Education, 48(5), 488-519.

Macedo, D. (1991). English only: The tongue-tying of America. Journal of Education, 173(2), 9-20.

Martin, D. B. (2007). Beyond missionaries or cannibals: Who should teach mathematics to African American children? The High School Journal, 91(1), 6-28.

Martin, D. B. (2009). Researching race in mathematics education. Teachers College Record, 111(2), 295338.

Martin, D. B. (2013). Race, racial projects, and mathematics education. Journal for Research in Mathematics Education, 44(1), 316-333.

Martin, D. B. (2019). Equity, inclusion, and antiBlackness in mathematics education. Race Ethnicity and Education, 22(4), 459-478.

McDermott, R., \& Varenne, H. (1995). Culture as Disability. Anthropology \& Education Quarterly, 26(3), 324-348.

* McGee, E. O. (2015). Robust and fragile mathematical identities: A framework for exploring racialized experiences and high achievement among black college students. Journal for Research in Mathematics Education, 46(5), 599-625.

McKinney de Royston, M., Vakil, S., Nasir, N. S., Miraya Ross, K., Givens, J., \& Holman, A. (2017). “He’s more like a 'brother' than a teacher": Politicized caring in a program for African American males. Teachers College Record, 119(4), 1-40.

Mendick, H. (2005). A beautiful myth? The gendering of being/doing 'good at maths.' Gender and Education, 17(2), 203-219. 
* Morvan, J. A. (2017). Making visible and acting on issues of racism and racialization in school mathematics. Brock Education: A Journal of Educational Research and Practice, 27(1), 35-52.

Moschkovich, J. (2002). A situated and sociocultural perspective on bilingual mathematics learners. Mathematical Thinking and Learning, 4(2-3), 189-212.

Nasir, N. S., Hand, V., \& Taylor, E. (2008). Culture and mathematics in school: Boundaries between "cultural" and "domain" knowledge in the mathematics classroom and beyond. Review of Research in Education, 32(1), 187-240.

Omi, Michael, and Howard Winant. (2014). Racial Formation in the United States. New York: Routledge.

Ong, M., Smith, J. M., \& Ko, L. T. (2017). Counterspaces for women of color in STEM higher education: Marginal and central spaces for persistence and success. Journal of Research in Science Teaching, 55(2), 206-245.

* Oslund, J. A. \& Barton, J. (2017). Creating zines: supporting powerful math identities. Mathematics Teaching in the Middle School, 23(1), 20-28.

Pais, A., \& Valero, P. (2012). Researching research: Mathematics education in the Political. Educational Studies in Mathematics, 80(1-2), 9-24.

* Parker, F., Bartell, T. G., \& Novak, J. D. (2017). Developing culturally responsive mathematics teachers: Secondary teachers' evolving conceptions of knowing students. Journal of Mathematics Teacher Education, 20(4), 385-407.

Philip, T. M., Olivares-Pasillas, M. C., \& Rocha, J. (2016). Becoming racially literate about data and dataliterate about race: Data visualizations in the classroom as a site of racial-ideological microcontestations. Cognition and Instruction, 34(4), 361-388.

Rooks, N. (2017). Cutting school: Privatization, segregation, and the end of public education. New York, NY: The New Press. 
Rosen, L. S. (2001). Calculating concerns: The politics of representation in California's" math wars". Unpublished PhD dissertation. University of California, San Diego.

Rubel, L. H. (2017). Beyond the dominant perspective. Journal of Urban Mathematics Education, 10(2), 66-105.

Rury, J. L., \& Saatcioglu, A. (2016). Opportunity hoarding. In The Wiley Blackwell encyclopedia of race, ethnicity, and nationalism (1st ed.). John Wiley \& Sons.

Schleppegrell, M. J. (2007). The linguistic challenges of mathematics teaching and learning: A research review. Reading \& Writing Quarterly, 23(2), 139-159.

Schoenfeld, A. (1988). When good teaching leads to bad results: the disasters of "well-taught" mathematics courses. Educational Psychologist, 23(2), 145-166.

Sengupta-Irving, T., Tunney, J., \& Macias, M. (in press). Stories of garlic, butter and ceviche: Surfacing contesta- tions and microaggressions in secondary STEM teacher professional development. Cognition and Instruction.

Setati, M. (2005). Teaching mathematics in a primary multilingual classroom. Journal for Research in Mathematics Education, 36(5), 447-466.

Silver, E. A., \& Herbst, P. G. (2007). Theory in mathematics education scholarship. In F. K. Lester (Ed.), Second handbook of research on mathematics teaching and learning (pp. 39-67). Reston, VA: National Council of Teachers of Mathematics.

Sleeter, C. E. (1987). Why is there learning disabilities? A critical analysis of the birth of the field in its social context. In T. Popkewitz (Ed.), The formation of school subjects: The struggle for creating an American institution (pp. 210-237). London, UK: Palmer Press.

Solórzano, D. G. (1998). Critical race theory, race and gender microaggressions, and the experience of Chicana and Chicano scholars. Qualitative Studies in Education, 11(1), 121-136. 
Stinson, D. W. (2004). Mathematics as "gate-keeper"(?): Three theoretical perspectives that aim toward empowering all children with a key to the gate. The Mathematics Educator, 14(1), 8-18.

* Tan, P. \& Kastberg, S. (2017). Calling for research collaborations and the use of dis/ability studies in mathematics education. Journal of Urban Mathematics Education, 10(2), 25-38.

* Turner, E. E., Gutiérrez, M. V., Simic-Muller, K., \& Diez-Palomar, J. (2009). "Everything is math in the whole world": Integrating critical and community knowledge in authentic mathematical investigations with elementary Latina/o students. Mathematical Thinking and Learning, 11(3), 136-157.

* Young, J., Young, J., Cason, M., Ortiz, N., Foster, M., \& Hamilton, C. (2018). Concept raps versus concept maps: A culturally responsive approach to stem vocabulary development. Education Sciences, 8(108).

Villegas, A. M. (1988). School failure and cultural mismatch: Another view. The Urban Review, 20(4), $253-265$.

Walkerdine, V. (1989). Femininity as performance. Oxford Review of Education, 15(3), 267-279.

Weis, L., \& Fine, M. (2012). Critical bifocality and circuits of privilege: Expanding critical ethnographic theory and design. Harvard Educational Review, 82(2), 173-201.

Yeh, C., Ellis, M., \& Mahmood, D. (2020). From the margin to the center: A framework for rehumanizing mathematics education for students with dis/abilities. Journal of Mathematical Behavior, 58(1).

* Zavala, M. (2017). Bilingual pre-service teachers grapple with the academic and social role of language in mathematics discussions. Issues in Teacher Education, 26(2), 49-66.

* Zevenbergen, R. (1996). Constructivism as a liberal bourgeois discourse. Educational Studies in Mathematics, 31(1-2), 95-113. 
Zevenbergen, R. (2003). Mathematics, social class and linguistic capital: An analysis of mathematics classroom interactions. In B. Allen \& S. Johnston-Wilder (Eds.), Mathematics education: Exploring the culture of learning (pp. 129-143). New York, NY: Routledge. 
Table 1

All Reviewed Articles

\section{Focal social category Math-specific articles (starred citations appeared in primary
corpus; the others were identified through reference searches
and recommendations)}

Ability - Boaler, J., Wiliam, D., \& Brown, M. (2000). Students' experiences of ability grouping-disaffection, polarisation and the construction of failure. British educational research journal, 26(5), 631-648.

- Lambert, R. (2015). Constructing and resisting disability in mathematics classrooms: A case study exploring the impact of different pedagogies. Educational Studies in Mathematics, 89(1), 1-18.

- Lewis, K. E. (2014). Difference not deficit: Reconceptualizing mathematical learning disabilities. Journal for Research in Mathematics Education, 45(3), 351-396.

- * Tan, P. \& Kastberg, S. (2017). Calling for research collaborations and the use of dis/ability studies in mathematics education. Journal of Urban Mathematics Education, 10(2), 25-38.

- Yeh, C., Ellis, M., \& Mahmood, D. (2020). From the margin to the center: A framework for rehumanizing mathematics education for students with dis/abilities. Journal of Mathematical Behavior, 58(1), 100758.

Class - Gutstein, E. (2009). The politics of mathematics education in the United States: Dominant and counter agendas. In B. Greer, S. Mukhopadhyay, A. B. Powell, \& S. Nelson-Barber (Eds.), Culturally Responsive Mathematics Education (pp. 137-163). New York, NY: Routledge.

- Stinson, D. W. (2004). Mathematics as "gate-keeper"(?): Three theoretical perspectives that aim toward empowering all children with a key to the gate. The Mathematics Educator, 14(1), 8-18.

- * Zevenbergen, R. (1996). Constructivism as a liberal bourgeois discourse. Educational Studies in Mathematics, 31(1-2), 95-113.

- Zevenbergen, R. (2003). Mathematics, social class and linguistic capital: An analysis of mathematics classroom interactions. In B. Allen \& S. Johnston-Wilder (Eds.), Mathematics education: Exploring the culture of learning (pp. 129-143). New York, NY: Routledge.

\section{Additional foundational works}

- Artiles, A. J. (2013). Untangling the racialization of disabilities: An intersectionality critique across disability models. Du Bois Review: Social Science Research on Race, 10(2), 329-347.

- Leonardo, Z., \& Broderick, A. A. (2011). Smartness as property: A critical exploration of intersections between whiteness and disability studies. Teachers College Record, 113(10), 2206-2232.

- McDermott, R., \& Varenne, H. (1995). Culture as disability. Anthropology \& Education Quarterly, 26(3), 324-348.

- Sleeter, C. E. (1987). Why is there learning disabilities? A critical analysis of the birth of the field in its social context. In T. Popkewitz (Ed.), The formation of school subjects: The struggle for creating an American institution (pp. 210-237). London, UK: Palmer Press.

- Freire, P. (2000). Pedagogy of the oppressed. New York, NY: Penguin Books. (Original work published 1970)

- Anyon, J. (1980). Social class and the hidden curriculum of work. Journal of Education, 162(1).

- Lareau, A. (1987). Social class differences in family-school relationships: The importance of cultural capital. Sociology of Education, 60(2), 73-85. 
Culture • * Ares, N. (2008). Cultural practices in networked classroom learning environments. International Journal of ComputerSupported Collaborative Learning, 3(3), 301-326.

- Bishop, A. J. (1990). Western mathematics: The secret weapon of cultural imperialism. Race \& Class, 32(2), 51-65.

- Boaler, J., \& Greeno, J. G. (2000). Identity agency and knowing in mathematics worlds. In J. Boaler (Ed.), Multiple Perspectives on Mathematics Teaching \& Learning. Westport, CT: Greenwood Press.

- Cobb, P., \& Hodge, L. L. (2011). Culture, identity, and equity in the mathematics classroom. In E. Yackel (Ed.), A Journey in Mathematics Education Research (Vol. 48, pp. 179-195).

- d'Ambrosio, U. (1985). Ethnomathematics and its place in the history of mathematics. For the Learning of Mathematics, 5(1), 44-48.

- * Ebby, C., Lim, V., Reinke, L., Remillard, J., Magee, E., Hoe, N., \& Cyrus, M. (2011). Community based mathematics project: Conceptualizing access through locally relevant mathematics curricula. Penn GSE Perspectives on Urban Education, 8(2), 11-18.

- * Francois, K. \& Stathopoulou, C. (2012). In-between critical mathematics education and ethnomathematics: A philosophical reflection and an empirical case of a Romany students' group mathematics education. Journal for Critical Education Policy Studies, 10(1), 234-247.

- * Kotsopoulos, D. (2014). The case of Mitchell's Cube: Interactive and reflexive positioning during collaborative learning in mathematics. Mind, Culture, and Activity, 21(1), 34-52.

- Louie, N. L. (2017). The culture of exclusion in mathematics education and its persistence in equity-oriented teaching. Journal for Research in Mathematics Education, 48(5), 488-519.

- Nasir, N. S., Hand, V., \& Taylor, E. (2008). Culture and mathematics in school: Boundaries between "cultural" and "domain" knowledge in the mathematics classroom and beyond. Review of Research in Education, 32(1), 187-240.

- * Oslund, J. A. \& Barton, J. (2017). Creating zines: supporting powerful math identities. Mathematics Teaching in the Middle School, 23(1), 20-28.

- * Parker, F., Bartell, T. G., \& Novak, J. D. (2017). Developing culturally responsive mathematics teachers: Secondary teachers' evolving conceptions of knowing students. Journal of Mathematics Teacher Education, 20(4), 385-407.

- * Young, J., Young, J., Cason, M., Ortiz, N., Foster, M., \& Hamilton, C. (2018). Concept raps versus concept maps: A culturally responsive approach to STEM vocabulary development. Education Sciences, 8(108).
- Gutiérrez, K. D., \& Rogoff, B. (2003). Cultural ways of learning: Individual traits or repertoires of practice. Educational Researcher, 32(5), 19-25.

- Ladson-Billings, G. (1995). But that's just good teaching! The case for culturally relevant pedagogy. Theory Into Practice, 34(3), 159165.

- Moll, L. C., Amanti, C., Neff, D., \& Gonzalez, N. (1992). Funds of knowledge for teaching: Using a qualitative approach to connect homes and classrooms. Theory Into Practice, 31(2), 132-141.

- Villegas, A. M. (1988). School failure and cultural mismatch: Another view. The Urban Review, 20(4), 253-265. 
Gender

- Boaler, J. (2002). Paying the price for "sugar and spice": Shifting the analytical lens in equity research. Mathematical Thinking and Learning, 4(2\&3), 127-144.

- Damarin, S., \& Erchick, D. B. (2010). Toward clarifying the meanings of "gender" in mathematics education research. Journal for Research in Mathematics Education, 41(4), 310-323.

- * Frost, J. H. \& Wiest, L. R. (2007). Listening to the girls: Participant perceptions of the confidence-boosting aspects of a girls' summer mathematics and technology camp. Mathematics Educator, 17(2), 31-40.

- Hottinger, S. N. (2016). Inventing the mathematician: Gender, race, and our cultural understanding of mathematics. Albany, NY: State University of New York Press.

- * Iwu, R. U. \& Azoro, A. V. (2017). A study on the barriers to participation of females in science, mathematics and technology education in Imo state: The way forward. Educational Research and Reviews, 12(17), 832-838.

- * Kahveci, A., Southerland, S. A., \& Gilmer, P. J. (2008). From marginality to legitimate peripherality: Understanding the essential functions of a women's program. Science Education, 92(1), 33-64.

- Leyva, L. A. (2017). Unpacking the male superiority myth and masculinization of mathematics at the intersections: A review of research on gender in mathematics education. Journal for Research in Mathematics Education, 48(4), 397.

- Mendick, H. (2005). A beautiful myth? The gendering of being/doing 'good at maths.' Gender and Education, 17(2), 203219.

- * Civil, M. (2014). Why should mathematics educators learn from and about Latina/o students' in-school and out-of-school experiences? Journal of Urban Mathematics Education, 7(2), 9-20.

- * de Araujo, Z., Roberts, S. A., Willey, C. \& Zahner, W. (2018). English learners in $\mathrm{K}-12$ mathematics education: A review of the literature. Review of Educational Research, 88(6), 879-919.

- Moschkovich, J. (2002). A situated and sociocultural perspective on bilingual mathematics learners. Mathematical Thinking and Learning, 4(2-3), 189-212.

- Schleppegrell, M. J. (2007). The linguistic challenges of mathematics teaching and learning: A research review. Reading \& Writing Quarterly, 23(2), 139-159.

- Setati, M. (2005). Teaching mathematics in a primary multilingual classroom. Journal for research in Mathematics Education, 447466.

- * Zavala, M. (2017). Bilingual pre-service teachers grapple with the academic and social role of language in mathematics discussions. Issues in Teacher Education, 26(2), 49-66.
- Haraway, D. J. (1991). Situated knowledges: The science question in feminism and the privilege of partial perspective. In Simians, Cyborgs, and Women: The Reinvention of Nature (pp. 183-201). New York, NY: Routledge.

- Walkerdine, V. (1989). Femininity as performance. Oxford Review of Education, 15(3), 267-279.

- Flores, N., \& Rosa, J. (2015). Undoing appropriateness: Raciolinguistic ideologies and language diversity in education. Harvard Educational Review, 85(2), 149-171.

- Macedo, D. (1991). English only: The tonguetying of America. Journal of Education, 173(2), 9-20. 
Race

- Adiredja, A. P. (2019). Anti-deficit narratives: Engaging the politics of research on mathematical sense making. Journal for Research in Mathematics Education, 50(4), 401.

- * Battey, D. \& Leyva, L. A. (2016). A framework for understanding whiteness in mathematics education. Journal of Urban Mathematics Education, 9(2), 49-80.

- Martin, D. B. (2007). Beyond missionaries or cannibals: Who should teach mathematics to African American children? The High School Journal, 91(1), 6-28.

- Martin, D. B. (2009). Researching race in mathematics education. Teachers College Record, 111(2), 295-338.

- Martin, D. B. (2013). Race, racial projects, and mathematics education. Journal for Research in Mathematics Education, 44(1), 316-333.

- Martin, D. B. (2019). Equity, inclusion, and antiblackness in mathematics education. Race Ethnicity and Education, 22(4), 459478.

- * McGee, E. O. (2015). Robust and fragile mathematical identities: A framework for exploring racialized experiences and high achievement among Black college students. Journal for Research in Mathematics Education, 46(5), 599-625.

- McKinney de Royston, M., Vakil, S., Nasir, N. S., Miraya Ross, K., Givens, J., \& Holman, A. (2017). “He's more like a 'brother' than a teacher": Politicized caring in a program for African American males. Teachers College Record, 119(4), 1-40.

- * Morvan, J. A. (2017). Making visible and acting on issues of racism and racialization in school mathematics. Brock Education: $A$ Journal of Educational Research and Practice, 27(1), 35-52.

- Rubel, L. H. (2017). Beyond the dominant perspective. Journal of Urban Mathematics Education, 10(2), 66-105.

- * Turner, E. E., Gutiérrez, M. V., Simic-Muller, K., \& Diez-Palomar, J. (2009). "Everything is math in the whole world": Integrating critical and community knowledge in authentic mathematical investigations with elementary Latina/o students. Mathematical Thinking and Learning, 11(3), 136-157.
- Delgado, R., \& Stefancic, J. (1995). Critical race theory: An introduction. New York, NY: New York University Press.

- Dumas, M. J. (2016). Against the dark: Antiblackness in education policy and discourse. Theory Into Practice, 55(1), 11-19.

- Harris, C. I. (1993). Whiteness as property. Harvard Law Review, 106(8), 1707-1791.

- Ladson-Billings, G., \& Tate, W. F. (1995). Toward a critical race theory of education. Teachers College Record, 97(1), 47-68.

- Solórzano, D. G. (1998). Critical race theory, race and gender microaggressions, and the experience of Chicana and Chicano scholars. Qualitative Studies in Education, 11(1), 121136. 
Intersecting identities
- * Bullock, E. C. (2018). Intersectional analysis in critical mathematics education research: A response to figure hiding. Review of Research in Education, 42(1), 122-145.

- * Frank, T. J. (2018). Teaching our kids: Unpacking an AfricanAmerican mathematics teacher's understanding of mathematics identity. Journal for Multicultural Education, 12(2), 144-160.

- * Gutiérrez, R. (2013). Why (urban) mathematics teachers need political knowledge. Journal of Urban Mathematics Education, 6(2), 7-19.

- * Gutiérrez, R. (2002). Enabling the practice of mathematics teachers in context: Toward a new equity research agenda. Mathematical Thinking and Learning, 4(2-3), 145-187.

- Gutiérrez, R. (2018). The need to rehumanize mathematics. In I. M. Goffney \& R. Gutiérrez (Eds.), Rehumanizing mathematics for Black, Indigenous, and Latinx students (pp. 1-10). Reston, VA: National Council of Teachers of Mathematics.

- * Ireland, D. T., Freeman, K. E., Winston-Proctor, C. E., DeLaine, K. D., McDonald Lowe, S., \& Woodson, K. M. (2018). (Un)hidden figures: A synthesis of research examining the intersectional experiences of Black women and girls in STEM education. Review of Research in Education, 42(1), 226-254.

- * Joseph, N. M., Hailu, M., \& Boston, D. (2017). Black women's and girls' persistence in the P-20 mathematics pipeline: Two decades of children, youth, and adult education research. Review of Research in Education, 41(1), 203-227.

- * Kitchen, R, Ridder, S. A., \& Bolz, J. (2016). The legacy continues: "The test" and denying access to a challenging mathematics education for historically marginalized students. Journal of Mathematics Education at Teachers College, 7(1), 17-26.

- * Langer-Osuna, J. (2015). Linear equations and rap battles: How students in a wired classroom utilized the computer as a resource to coordinate personal and mathematical positional identities in hybrid spaces. Mathematics Education Research Journal, 27(1), 51-64.

- * Leonard, J., Brooks, W., Barnes-Johnson, J., \& Berry, R. Q. (2010). The nuances and complexities of teaching mathematics for cultural relevance and social justice. Journal of Teacher Education, 61(3), 261-270.

- * Leyva, L. A. (2016). An intersectional analysis of Latin@ college women's counter-stories in mathematics. Journal of Urban Mathematics Education, 9(2), 81-121.
- Collins, P. H., \& Bilge, S. (2016). Intersectionality. Malden, MA: Polity Press.

- Crenshaw, K. W. (1991). Mapping the margins: Intersectionality, identity politics, and violence against women of color. Stanford Law Review, 43(6), 1241-1299. 
Table 2

Theories of Marginalization in Primary Corpus

\section{Citation}

Ares, N. (2008). Cultural practices in networked classroom learning environments. International Journal of ComputerSupported Collaborative Learning, 3(3), 301-326.

Battey, D. \& Leyva, L. A. (2016). A framework for understanding Whiteness in mathematics education. Journal of Urban Mathematics Education, 9(2), 49-80.

Bullock, E. C. (2018). Intersectional analysis in critical mathematics education research: A response to figure hiding. Review of Research in Education, 42(1), 122-145.

Civil, M. (2014). Why should mathematics educators learn from and about Latina/o students' in-school and out-of-school experiences? Journal of Urban Mathematics Education, 7(2), 9-20.

de Araujo, Z., Roberts, S. A., Willey, C. \& Zahner, W. (2018). English learners in $\mathrm{K}-12$ mathematics education: A review of the literature. Review of Educational Research, 88(6), 879919.

Ebby, C., Lim, V., Reinke, L., Remillard, J., Magee, E., Hoe, N., \& Cyrus, M. (2011). Community based mathematics project: Conceptualizing access through locally relevant mathematics curricula. Penn GSE Perspectives on Urban Education, 8(2), 11-18.

Francois, K. \& Stathopoulou, C. (2012). In-between critical mathematics education and ethnomathematics: A philosophical reflection and an empirical case of a Romany students' group mathematics education. Journal for Critical Education Policy Studies, 10(1), 234-247.

\section{Focal social Primary disciplinary perspective on category}

Culture

Race

Intersecting identities

Language

Language

Culture

Culture

Cultural: The features of school mathematics are privileged over students' culture. 